\title{
THỰC PHẨM CHỨC NĂNG-THỨC ĂN CỦA CON NGƯờI Ở THẾ KỶ 21. ÚNG DỤNG CÔNG NGHỆ SINH HỌC TẠO CÁC CHẾ PHẨM THỰC PHẨM CHỨC NĂNG PHỤC VỤ SỨC KHỎE CỦA CộNG ĐỒNG
}

\author{
NGUYỄN TÀI LƯƠNG \\ Viện Công nghệ sinh học
}

Thuật ngữ thực phẩm chức năng (TPCN) được dùng để chỉ những chế phẩm thực phẩm có chứa các chất có hoạt tính sinh học cao, có dược tính từ động vật, thực vật và vi sinh vật, một số chất tổng hợp giống các hoạt chất tự nhiên (như vitamin, hương liệu...), có tính chất thiết dụng cần cho các hoạt động chức năng của từng hệ, từng cơ quan hay toàn bộ cơ thể và phòng chống một số bệnh. TPCN không thay thế thuốc chữa bệnh, nhưng nằm ở ranh giới giữa thực phẩm và thuốc chữa bệnh.

Định nghĩa chung về TPCN (Functional foods) mang tính toàn cầu đã được thống nhất tại Hội nghị các nước châu Âu tổ chức tại Rôma năm 1984 như sau: "TPCN là thực phẩm có lợi cho một hay nhiều hoạt động của cơ thể hơn là so với giá trị dinh dướng của nó mang lại, như cải thiện tình trạng sức khoẻ và giảm nguy cơ mắc bềnh".

Tùy theo quan niệm của mỗi nước, ở châu Âu người ta gọi TPCN là thực phẩm-thuốc (medical food) hoặc dược phẩm dinh dưỡng (nutraceutics), thực phẩm bổ sung dinh dưỡng (food suplements); Trung Quốc gọi là "thực phẩm bổ dương bảo vệ sức khỏe"; Việt Nam gọi chung là "thưc phẩm đặc biệt".

Theo dự báo của các chuyên gia, thì "Thức ăn của con người trong thế kỷ 21 là thực phẩmthuốc". Thức ăn không chỉ đảm bảo đủ calo, ăn ngon, ăn sạch, mà còn phải chứa các hoạt chất sinh học (HCSH) tự nhiên nào đó cần cho sức khỏe và sắc đẹp, không chỉ điều khiển được các hoạt động chức năng của từng hệ, từng cơ quan trong cơ thể, điều hòa nhịp sinh học, tạo ra cho con người khả năng đáp ứng miễn dịch cao, chống sự già hóa, kéo dài tuổi thọ, mà còn phòng chống được một số bệnh liên quan đến ăn uống, kể cả một số bệnh mãn tính. Như vậy là, để có sức khỏe tốt và bền vững, con người cần quan tâm lựa chọn thành phần dinh dưỡng từ thức ăn phổ biến hàng ngày và nguồn $\mathrm{TPCN}$ có chứa các $\mathrm{HCSH}$ mà mình mong muốn. Con người ở thế kỷ 21 thiên về lý tính sẽ không chỉ uống và ăn cho no, mà rất coi trọng tính hợp lý của việc ăn uống.

Con người của thế giới đương đại thường mắc 5 loại bệnh có tỷ lệ tử vong cao do dinh dưỡng không hợp lý, mất cân đối các chất dinh dưỡng trong khẩu phần ăn hàng ngày; đó là: bệnh động mạch vành, một số bệnh ung thư do nguyên nhân ăn uống, choáng đột quy, đái đường và xơ vữa động mạch. Kết quả điều tra dịch tễ học này của nước Mỹ đã thúc đẩy sự ra đời của nhiều loại $\mathrm{TPCN}$ dành cho từng loại bệnh nhân.

Công ty Sakyo Nhật Bản đã cho ra thị trường loại thức ăn làm đẹp người (cosmetic foods) như nước uống chống nếp nhăn colagien, kẹo canxi phomat aloevera làm mịn da và nhiều sản phẩm kỳ diệu khác được sản xuất cho người có quá nhiều axit và huyết áp cao. Chế phẩm từ vây cá mập làm tăng cường khả năng miễn dịch cho cơ thể. Chế phẩm từ thịt rùa có khả năng chống tai biến mạch máu não. Thực phẩm "thông minh" đã xuất hiện ở Châu Âu có chứa những HCSH cần cho hoạt động của một số cấu trúc của bộ não. Các chế phẩm chống bất lực và chống già hóa khá phong phú, được bào chế từ các HCSH như hócmôn testsoteron từ tinh hoàn của động vật, selen hữu cơ, carôtenôit, các vitamin $\mathrm{A}, \mathrm{C}, \mathrm{E}$. Viện Thực phẩm và Dinh dưỡng Balan đã cho ra đời một loại "bánh ngọt" được chế từ nhiều loại rau quả có tác dụng giảm béo. Các nhà khoa học thuộc McGill School of Dietetics and Human tại Montrêal tổng hợp được và đưa ra thị trường một loại dầu ăn có tác 
dụng giảm côlextêrôn và chống béo phì. Tại các nước Âu Mỹ và Nhật Bản, những loại đồ uống được mọi người ưa thích là các loại nước quả có bổ sung vitamin và các chất khoáng, trong đó có loại nước uống đặc biệt dành riêng cho các vận động viên thể dục thể thao. Loại cà phê có bổ sung tinh chất của nhân sâm của Công ty Jeremiah's Pick Cofee, có tác dụng kích thích sự hưng phấn của thần kinh và cải thiện trí nhớ. Hãng Côca Côla tung ra thị trường châu Âu loại nước giải khát chức năng với tên thương mại là Powerada cũng được người tiêu dùng đón nhận một cách khá nồng nhiệt.

Trên thị trường đã có không ít các sản phẩm TPCN của Trung Quốc chỉ định dùng cho vận động viên như Hải văn huyết nguyên (chế biến từ con ốc vằn), Tinh hoa khẩu phục dịch (dung dịch uống từ hoạt chất có cấu trúc phân tử 1-6 fructoza diphotphat), Dung dịch cường lực sĩ (thuốc bổ thận), Viên nang ngự lộc tinh (từ máu hươu + giao cổ lan + phục linh), Chế phẩm Khang Thai (sản phẩm hợp tác Mỹ-Trung dùng cho vận động viên) ... Trên thị trường Việt Nam còn xuất hiện một số loại thực phẩm-thuốc nhập từ nước Pháp và Hàn Quốc như Ribozinc, Stimol, Belaf... cung cấp cho cơ thể các nguồn bổ sung vi chất dinh dưỡng, vitamin và chất khoáng.

Trên thị trường hiện nay, khá phong phú các loại TPCN, song tựu trung có thể phân chia thành 3 nhóm :

1. Nhóm TPCN có nguồn gốc tự nhiên: từ động vật, thực vật và vi sinh vật mà trong bản thân chúng có chứa các HCSH có tác dụng tích cực đối với cơ thể như cà rốt, gấc có chứa $\beta$ carôten có tác dụng chống lão hoá, phòng ngừa ung thư, làm sáng mắt. Rong tảo giầu axit amin và vitamin có tác dung giảm béo, giảm côlextêrôn trong máu. Trà xanh có fluo diệt vi khuẩn, làm bền răng, có catechin giúp chống ung bướu, chống xơ vữa thành mạch.

2. Nhóm TPCN là sản phẩm của quá trình chế biến không có chất bổ sung như các sản phẩm từ sữa-sữa chua, phomát, có tác dụng kích thích tiêu hóa, điều hòa huyết áp và tăng khả năng miễn dịch. Trong quá trình lên men, ngoài việc tạo ra các peptit có hoạt tính thì một số lượng lớn vi khuẩn lactíc lại là yếu tố sinh học có giá trị làm trẻ hóa cơ thể.
3. Nhóm TPCN đã qua chế biến bằng công nghệ cao và có bổ sung các HCSH có nguồn gốc tự nhiên từ động vật, thực vật, vi sinh vật, các vitamin và chất khoáng. Đây chính là thành quả của công nghê y sinh hoc hiên đai. Các HCSH đưa vào thực phẩm có thể điều khiển được hoạt động của từng hệ, từng cơ quan trong cơ thể, nâng cao sức đề kháng của cơ thể. Vấn đề lý thú là hiện nay, các nhà quân sự đang có yêu cầu đưa các yếu tố trí nhớ vào $\mathrm{TPCN}$ và điều này rất quan trọng bởi vì trong chiến tranh hiện đại, cần cơ động cao, hỏa lực mạnh, tác chiến điện tử và với các thiết bị vũ khí công nghệ cao rất cần trí nhớ và sự thông minh của binh sỹ để giành thắng lợi nhanh, cả trong tiến công và phòng ngự.

Hiện nay, nhân dân các nước trên thế giới có xu hướng ưa chuộng dùng các TPCN hơn dùng thuốc, với quan điểm phòng bệnh hơn chữa bệnh. Riêng người Nhật Bản tiêu thụ 4,5 tỷ USD mỗi năm cho các loại TPCN. Chính vì vậy, đa số các tập đoàn sản xuất thuốc đang chuyển sang sản xuất $\mathrm{TPCN}$ và tìm được đối tượng tiêu thụ lớn hơn. Các chuyên gia kinh tế đã tính toán rằng doanh thu bán ra các loại TPCN hay thực phẩm-thuốc hàng năm đã vượt con số khoảng 100 tỷ USD.

Tai Việt Nam, sản xuất TPCN trên cơ sở ứng dụng công nghệ sinh học (CNSH) nâng cấp công nghệ y học cổ truyền, cũng đã được quan tâm từ thập niên 90 của thế kỷ XX. Đó là các sản phẩm của xưởng sinh học nghiên cứu và sản xuất các sản phẩm động vật quý hiếm (do Thủ tuớng Võ Văn Kiệt phê duyệt) thuộc Trung tâm Sinh lý-Hoá sinh người và động vật, Viện Khoa học Việt Nam: pantôcrin từ nhung hươu sao, các loại rượu bổ tam xà, ngũ xà, tắc kè, hải sâm, yến sào vv... Các loại rượu được sản xuất bằng công nghệ enzym, trong đó, công nghệ sản xuất rượu tam xà có năng suất, chất lượng cao gấp 4 lần so với công nghệ cổ truyền, được người Việt Nam và người nước ngoài ưa thích. Sản phẩm đã được nhận huy chương vàng tại Hội chợ Triển lãm thành tựu kinh tế kỹ thuật, Hà Nội năm 1995. Những năm gần đây, một số sản phẩm từ tài nguyên sinh vật rừng và biển đã được sản xuất dưới dạng viền nang, viên nén, dung dịch uống... trên dây chuyền hiện đai tại các xí nghiệp dược phẩm trong nước. Các sản phẩm này là kết quả nghiên cứu nghiêm túc của các 
chương trình khoa học công nghệ của các viện nghiên cứu, quân Y viện 103 , cục Quân nhu và các trường đại học trong nước. Đó là các chế phẩm nhuận gan, lợi mật, tạo máu, dưỡng não, sáng mắt, phòng chống ung thư, đặc biệt là các chế phẩm viên nang hải sâm, rắn biển, trà sâm cúc, đinh lăng, tảo xpirulina, lương khô dưới dạng TPCN tăng lực cho vận động viên và lực lượng vũ trang được sản xuất và được đông đảo người tiêu dùng hưởng ứng.

Việc ứng dụng CNSH trong sản xuất thuốc và thực phẩm-thuốc đang được quan tâm đặc biệt tại các nước trong khu vực. Malaixia xây dựng Viện $\mathrm{CNSH}$ dược phẩm nằm trong "Thung lüng CNSH-Bio Valley"; Trung Quốc xây dựng "Thung lũng thuốc" lớn nhất thế giới để sản xuất dược phẩm và là nước có nhiều thành công nâng cấp công nghệ $\mathrm{y}$ dược cổ truyền thành công nghêe cao. Trung Quốc có tới 1 van loạ TPCN khác nhau với tổng giá trị hàng năm ước tính khoảng 2,5 tỷ USD.

Việc nghiên cứu tính đa dạng của bản đồ gien của người thuộc các sắc tộc đang bắt đầu được tiến hành tại một số nước châu Á và ở Việt Nam. Theo kỹ thuật mới, có thể phân biệt tới 50.000 khác biệt trong gien, không chỉ giúp chúng ta làm sáng tỏ các mô hình di cư của các tộc người trong lịch sử, mà vấn đề rất lý thú là giải thích nguyên nhân bệnh do gien.

Việc xây dựng cơ sở dữ liệu gien sẽ thúc đẩy công nghiệp dược phát triển với định hướng nghiên cứu tạo ra các nguồn nguyên liệu quý cho công nghiệp dược. Hiện nay, CNSH đã có thể tạo ra các giống cây biến đổi gien có hàm lượng các $\mathrm{HCSH}$ cao gấp hàng trăm lần so với cây bình thường như cà rốt giầu carôten, rau thì là giầu vitamin $\mathrm{C}$, rau bí giầu chất sắt, nho đỏ giầu selen, cà chua giầu flavonoit vv... Đó là các chất có tác dụng kháng ôxy hóa và phòng chống ung thư, có thể sử dụng để bào chế đưa vào TPCN .

Những thành tựu của công nghệ enzym-một mũi nhọn của CNSH trong lĩnh vực tạo ra các peptit có chuỗi ngắn, có trọng lượng phân tử thấp và có hoạt tính sinh lý, đang mở triển vọng mới đóng góp cho sự phát triển của công nghiệp chế biến thực phẩm-chức năng, theo hướng điều khiển các hệ enzym trong cơ thể; thí dụ, dipeptit (Ile-Tyr)-ức chế ACE (enzym chuyển hoá antegiotensin) tách chiết từ thịt của cá cơm, cá mòi. Chế phẩm loại này có thể giúp ngư dân, bộ đội hải quân, thợ lặn làm việc lâu dưới biển vào mùa đông mà vẫn ấm người và không bị tăng huyết áp.

Có thể dự báo rằng trong tương lai các loại thực phẩm phân tử sẽ thịnh hành. Nó được điều chế từ nhiều chất dinh dưỡng giầu $\mathrm{HCSH}$ và các phân tử peptit có hoạt tính, có thể giúp chúng ta phòng ngừa mọi bệnh tật, khiến cơ thể vận hành lành mạnh theo đúng thuyết về gien và di truyền.

Tóm lại, nhiều phụ gia là các nguồn hoạt chất sinh học tự nhiên từ động vật, cây cỏ và vi sinh vật... được chế biến đưa vào thành phần TPCN, lại có thể điều khiển được chức năng của từng hệ, từng cơ quan trong cơ thể và phòng chống một số bệnh, kể cả bệnh hiểm nghèo (tăng tạo máu, tăng trí nhớ, tăng hoạt động cơ bắp, tăng miễn dịch, chống già hóa, chống "bất lực," chống thụ thai, cai nghiện, phòng ngừa ung thư....). Có thể nói không phóng đại rằng, ngày nay các chất dinh dưỡng chính (protein, đường, lipit...) lại trở thành phụ, và các hoạt chất sinh học đưa vào thực phẩm lại trở thành chính yếu. Các thức ăn mới này chính là các loại thực phẩm-thuốc hay thực phẩm chức năng, sẽ góp phần cư thể hóa một nguyện vọng xa xưa của loài người trên trái đất này là thức ăn của chúng ta sẽ là những vị thuốc của chúng ta!

Cũng cần phải nhấn mạnh thêm rằng, hiện nay hiệu quả của nhiều TPCN mới dựa trền những nguyên lý sinh hóa chung và một nghệ thuật máckétting nhằm đánh vào tâm lý của người tiêu dùng, hơn là dựa trên những nghiên cứu nghiêm túc có tính chất thuyết phục. Thí dụ, khi sử dụng "viên tình yêu", "trà giảm béo" và một số chế phẩm khác, người ta đã phát hiện có những phản ứng phụ.

\section{VIÊC KHAI THÁC CÁC TÀI NGUYÊN SINH HOC CỦA ĐẤT NƯớC, CÁC KINH NGHIÊM CỦA NỀN Y HOC DÂN TộC, KẾT HợP VỚI VIÊC ÚNG DUNG CNSH TAO CÁC CHẾ PHẨM THỰC PHẨM CHỨC NĂNG Ở VIÊT NAM LÀ LĨNH VỰC CÓ NHIỀU LỢI THẾ}

Vấn đề lý thú là thế giới đương đại có xu hướng quay về với các hợp chất thiên nhiên có trong động vật và cây có̉ họ muốn khai thác kinh nghiệm y học cổ truyền và nền văn minh ẩm thực của các dân tộc phương Đông, hạn chế 
tối đa việc đưa các hóa chất vào cơ thể-thủ phạm của các phản ứng phụ, quen thuốc, nhờn thuốc (hiện nay, 90-95\% các nhóm chất quan trọng như kháng sinh, các loại vitamin, các nội tiết tố... có nguồn gốc hóa học tổng hợp).

Đối với nước ta, việc nghiên cứu tạo ra các chế phẩm thực phẩm-thuốc với phương châm "công nghệ cao, bản sắc cổ truyền" là hướng nghiên cứu rất lý thú và có lợi thế, vì lẽ chúng ta có thế mạnh về tài nguyên sinh học nhiệt đới và có kho tàng kinh nghiệm phong phú của nền $\mathrm{y}$ học dân tộc; từ việc sử dụng bột cóc làm thuốc chống bệnh còi xương cho trẻ em, việc sử dụng côn trùng và các động vật rừng với mục đích bổ dưỡng và làm thuốc chữa bệnh, đến việc sử dụng nhiều loại sản phẩm biển có giá trị dỉnh dưỡng cao, dược liệu quý, có tác dụng "hồi xuân cường lực, cải lão hoàn đồng" như "nhất yến sào, nhì bào ngư", món ăn "bát trân" gồm 8 loại hải sản quý (yến sào, bào ngư, hải sâm, vây cá, các nhuyễn thể biển) phục vụ các bữa yến tiệc trong cung đình $\mathrm{vv}$... Kho tàng kinh nghiệm này không ngừng được bổ sung từ thế hệ này sang thế hệ khác trong quá trình lao động sản xuất, chinh phục thiên nhiên và đang được nền y sinh học hiện đại soi sáng, chứng minh.

Biển Việt Nam không chỉ là một kho thực phẩm lớn, mà còn là một kho thuốc vô tận. Người Việt Nam sống trên 2 kho thuốc (rừng và biển) nhưng vẫn thiếu thuốc, thật là một nghịch lý!

THÀNH CÔNG BƯớC ĐẦU TRONG VIÊC NGHIÊN CỨU THỰC PHẨM CHỨC NĂNG. CÁC CHẾ PHẨM TẰNG LỰC ĐẦU TIÊN CHO VẬN ĐộNG VIÊN VIỆT NAM

Trong thể thao, việc sử dụng các kích thích tố hóa học tổng hợp đều bị cấm nghiêm ngặt. Vì vậy, việc nghiên cứu, tìm kiếm, khai thác các nguồn hoạt chất sinh học với mục đích tăng cường thể lực cho vận động viên đang trở thành một cuộc ganh đua thầm lặng và mang tính bí mật giữa các quốc gia, thậm chí giữa các tỉnh, các bang trong một quốc gia. Điều này dễ hiểu vì nó liên quan đến số lượng huy chương giành được.

Việc tìm kiếm các nguồn HCSH biển, nhóm nghiên cứu của chúng tôi thuộc phòng Hoá sinh protein,Viện Công nghệ sinh học đã tiến hành phân tích sinh hóa 4 loài hải sâm ăn được
(Holothuria scabra, Actynopyga echinites, Pachithyon rubra, Bahachia graeffei), 4 loài rắn biển ăn được (Lapemis hardwwickii Gray, Hydrophys cyanocintus, Microcephalophys gracillis, Praescula viperina) và loài cầu gai (Echinoidea). Chúng tôi đã phát hiện được một số HCSH quan trọng có trong thị của chúng, mà chưa thấy có tài liệu nào công bố [các hócmôn stêroit, các glucôzit tritécpen, carôtenôit, nơrôpeptit, các axit amin không thay thế được, các nguyên tố vi lượng có hoạt tính sinh lý (Fe, $\mathrm{Zn}, \mathrm{Cu}, \mathrm{Se} . .)$.$] . Các phát hiện mới này đã$ tạo cơ sở khoa học để soi sáng các kinh nghiệm y học cổ truyền và vấn đề quan trọng là đã dẫn chúng tôi đến các giải pháp khoa học công nghệ để sản xuất được một số các chế phẩm thực phẩm-thuốc phục vụ việc tăng cường sức khỏe cho vận động viên, lực lượng vũ trang và người lao động. Đó là các chế phẩm viên nang Hasaton từ hải sâm, Rabiton và Rabitam từ rắn biển, Hagaton từ hải long, cầu gai.

Những sinh vật biển này có trữ lượng lớn ở nước ta. Hải sâm phân bố nhiều ở vùng biển của các tỉnh Khánh Hòa, Phú Yên, Bình Thuận, Kiên Giang, Vũng Tàu-Côn đảo, Thanh Hóa... Rắn biển ở nước ta cũng có trữ lượng lớn, tại Nha Trang, có thể khai thác 7 tấn rắn/năm. Các nguồn lợi này lâu nay mới được khai thác và chế biến thô để xuất khẩu, nên có giá trị thấp. Hiện nay, Viện Nghiên cứu thuỷ sản 3 Nha Trang đang tiến hành gây nuôi có kết quả loài hải sâm cát. Việc phát triển $\mathrm{CNSH}$ biển sẽ mở ra khả năng ứng dụng các kỹ thuật nhân bản hoặc nuôi cấy tế bào gốc từ các động vật biển kể trên, để thu nhận các nguồn hoạt chất quý, phục vụ cho công nghiệp dược của nước ta.

Công nghệ sản xuất các chế phẩm được tiến hành trên dây chuyền hiện đại của các công ty dược như chế phẩm sinh học Biopha, xí nghiệp dược trung ương 25 tại Tp. Hồ Chí Minh, công ty cổ phân dược Traphaco tại Hà Nội. Các chế phẩm đã đăng ký chất lượng hàng hóa tại Cục vệ sinh an toàn thực phẩm, Bộ Y tế và đã được Cục quản lý dược, Bộ Y tế cấp giấy phép sản xuất lưu hành trên thị trường trong toàn quốc.

Tác dụng $\mathrm{y}$ sinh học của các chế phẩm trên đã được nghiên cứu kỹ trong các mô hình thực nghiệm trên động vật, nghiên cứu trên lâm sàng tại bệnh viện Bạch Mai, Hà Nội và cuối cùng ứng dụng trên vận động viên thể dục thể thao. 
5 năm qua, các chế phẩm viên nang hải sâm, rắn biển đã được ứng dụng có hiệu quả với hàng trăm vận động viên thể dục thể thao của nước ta, không thây có phản ứng phụ; nhiều vận động viên đã đạt thành tích cao trong các cuộc thi đâu khu vực và quốc tế.

Tại SEAGames-20 tổ chức tại Brunây tháng 8 năm 1999, các vận động viên võ thuật Pencak silat dùng viên nang hải sâm đều có cải thiện về thể lực, thi đấu thành công, đoạt 4 huy chương vàng (Đặng Văn Chín, Đặng Thị Thuý, Trịnh Thị Mùi, Nguyễn Văn Hùng) và 1 huy chương bạc (Đào Xuân Thắng).

Gần đây, tại SEAGames-22 năm 2003 được tổ chức tai Việt Nam, 550 vân động viên Việt Nam đã sử dụng các chế phẩm viên nang hải sâm, rắn biển, trong đó có 85 người đoạt huy chương vàng, 91-huy chương bạc, 70-huy chương đồng. Khi kiểm tra doping, tất cả các vđv đều cho kết quả âm tính. Cần lưu ý rằng trước đây, đoàn thể thao Việt Nam đã dùng thuốc tăng lực Khang Thai với giá 4 USD/1 gói; một ngày dùng 2 gói, mất 8 USD. Mỗi vận động viên sử dụng 2 tháng trước khi thi đấu mất 480 USD. Trong khi đó, sử dụng viên nang hải sâm hay rắn biển chỉ mất 2000đ/1 viên, tức 6000đ/người/ngày, chỉ hết 180.000đ/tháng, 2 tháng mất tương đương 22,8 USD cho 1 vận động viên. Nếu hàng triệu vận động viên sử dụng sản phẩm nội địa, sẽ tiết kiệm được hàng trăm triệu đô la cho đất nước.

Tổng quan một số thông tin mới trong lĩnh vực TPCN, có thể thấy rằng việc ứng dụng công nghệ cao trong nghiên cứu và sản xuất $\mathrm{TPCN}$ là một hướng nghiên cứu lớn và mới của thế giới, có ý nghĩa khoa học và thực tiễn lớn. Đi theo hướng này, các nhà khoa học Việt Nam đang vào cuộc và có thể hội nhập. Đây thực sự là hướng nghiên cứu rất lý thú, lại có lợi thế vì chúng ta có kho tàng kinh nghiêm phong phú của nền y học dân tộc và có thế mạnh về các tài nguyên sinh vật nhiệt đới. Những kết quả nghiên cứu bước đầu về TPCN ở trong nước có ý nghĩa kinh tế, xã hội nhân văn lớn, có triển vọng đóng góp có hiệu quả cao cho sự phát triển của công nghiệp dược của nước ta. Có thể dự kiến thực phẩm trong tương lai dùng cho nhân dân và bộ đội phải là thực phẩm cho năng lượng cao, có thể tích nhỏ, thuận lợi cho việc vận chuyển, không phải nấu nướng và khẩu vị phải đa dạng hóa. Các yếu tố trí nhớ và nâng cao sức đề kháng, sức chống chịu của cơ thể vv... sẽ được đưa vào $\mathrm{TPCN}$ dùng cho nhân dân, người lao động trí óc, đặc biệt cho bộ đội trong các cuộc hành quân thần tốc và trong tác chiến trong tình hình mới. Các loại đồ hộp và thực phẩm đóng gói ăn nhanh sẽ đự̛̣c thay thế dần bằng TPCN. Các kiểu ăn uống mang tính phòng và chữa bệnh đều được vận dụng trong đời sống. Chúng tôi kiến nghị với Nhà nước nên đặt hàng cho các nhà khoa học trong lĩnh vực này, nghiên cứu tạo ra nhiều mặt hàng TPCN mới, với phương châm "công nghệ cao, bản sắc cổ truyền" vì sức khoẻ của cộng đồng, vì hạnh phúc của nhân dân, nhằm góp phần đưa các nghị quyết của Đảng và của Quốc hội vào cuộc sống.

\section{TÀI LIÊU THAM KHẢO}

1. Andy Organ, 2003: Dùng dược phẩm đặc biệt phục vụ quân đội. (theo Splegel.) An ninh thế giới, 104: 338. Hà Nội

2. Đàm Trung Bảo, Hoàng Tích Huyền, Phạm Nguyên Vinh, 1999: Chất chống oxy hoá để phòng chống bệnh tật và chống lão hoá. Nxb. Y học, Hà Nội.

3. Dương Nghiệp Chí, Nguyễn Ngọc Cừ, 2000: Mệt mỏi hồi phục và dinh dưỡng vận động viên. Viện KH TDTT, Hà Nội.

4. Nguyễn Thành Đồng, 2003: Nghiên cứu ảnh hưởng của Fenobucarb và tác dụng bảo vệ của hải sâm lên một số chỉ số sinh học ở động vật thực nghiệm. Luận án tiến sỹ $\mathrm{y}$ học. Hà Nội.

5. Phan Thị Kim, Bùi Minh Đức, 2002: Thực phẩm, Thực phẩm chức năng an toàn và sức khoẻ bền vững. Nxb. Y học, Hà Nội.

6. Hoàng Thị Ái Khuê, 2005: Nghiên cứu tác dụng của viên nang hải sâm và rabiton lên một số chỉ tiêu sinh lý, hoá sinh và thành tích của nam vận động viên điền kinh. Luận án tiến sỹ sinh học, Hà Nội.

7. Ngô Ung Long, 1985: Tác dụng của đinh lăng về sinh thích nghi, nâng cao sức bền bỉ, dẻo dai trong luyện tập bộ binh, sức chịu đựng với nóng, độc xạ. Báo cáo khoa học, Hội nghị Y sinh học vũ trụ, Viện Khoa học Việt Nam, Hà Nội. 
8. Đỗ Tất Lợi, 1991: Những cây thuốc và vị thuốc Việt Nam. Nxb. Khoa học và Kỹ thuật, Hà Nội.

9. Nguyễn Tài Lương và cs., 2001: Úng dụng công nghệ sinh học sản xuất cá $\mathrm{c}$ chế phẩm thực phẩm-thuốc cho vận động viên. Hội thảo quốc tế về sinh học, 2: 297-284, Hà Nội.

10. Nguyễn Thiện Luân, Lê Doãn Diên, Phan Quốc Kinh, 1997: Các loại thực phẩm thuốc và thực phẩm chức năng ở Việt Nam. Nxb. Nông nghiệp, Hà Nội.

11. Country Reports on Functional food in Asean and China, 24-26/9/2002: Beijing, P. R. China.

12. Tổng cục Thống kê, 1999: Dự báo thế kỷ 21. Nxb. Thống kê, Hà Nội.

13. Trần Ngọc Chương, 1998: Thực phẩm trong tương lai. Báo Khoa học \& Đời sống, số 435 .

\section{Thông báo của Tạp chí Sinh học về việc tăng số trang của Tạp chí}

Trước tình hình phát triển mạnh mẽ của ngành Sinh học ở nước ta, để đáp ứng nhu cầu công bố các công trình nghiên cứu của các nhà Sinh học và để mở rộng thể tài của Tạp chí, kể từ số 1 (tập 27) năm 2005, được phép của Bộ Văn hóa-Thông tin, Tạp chí Sinh học sẽ tăng số trang lên 96 trang/số.

Chúng tôi xin thông báo để bạn đọc biết và rất mong tiếp tục nhận được sự cộng tác chặt chẽ của các nhà Sinh học để Tạp chí Sinh học ngày một phong phú và hấp dẫn hơn. 